\title{
An Autopsy Study of Organophosphorus Compound Poisoning At Sylhet MAG Osmani Medical College
}

Kishoara Binte Quader ${ }^{1 *}$, Parveen Sultana ${ }^{2}$, Iffath Farooqui ${ }^{3}$, Md. Syedur Rahaman Sumon ${ }^{4}$, Md. Nur Hossain ${ }^{5}$, Md. Shamsul Islam ${ }^{6}$, Jannatul Ferdous ${ }^{7}$

${ }^{1}$ Assistant Professor, Dept. of Forensic Medicine, Delta Medical College, Dhaka, Bangladesh

${ }^{2}$ Assistant Professor, Dept. of Forensic Medicine, Enam Medical College, Savar, Dhaka, Bangladesh

${ }^{3}$ Assistant Professor, Dept. of Forensic Medicine, Sylhet Women's Medical College, Sylhet, Bangladesh

${ }^{4}$ Assistant Professor, Dept of forensic Medicine, Bashundhara Ad- din Medical College, Dhaka, Bangladesh.

${ }^{5}$ Professor and Head, Dept. of Forensic Medicine, Delta Medical College, Dhaka, Bangladesh

${ }^{6}$ Assistant Professor, Dept. of Forensic Medicine, Sylhet Mag Osmani Medical College, Sylhet, Bangladesh

${ }^{7}$ Lecturer, Dept. of Forensic Medicine, Dhaka Medical College, Dhaka, Bangladesh

DOI: $10.36347 /$ sjams.2020.v08i05.018

| Received: 24.04.2020 | Accepted: 01.05.2020 | Published: 14.05.2020

*Corresponding author: Kishoara Binte Quader

Abstract

Original Research Article

Objective: In this study our main goal is evaluation of autopsy study of organo phosphorus poisoning in patients. Method: This retrospective type of study was conducted among 75 patients who fulfilled criteria from Sylhet MAG Osmani Medical College from January 2015 to January 2017. Results: During the study, 57\% patients were male, which was $14 \%$ higher than female. $50 \%$ worked as an agriculture area/ farmer. Also, $75 \%$ people used organo phosphorus for suicide and $25 \%$ people used it accidentally. Conclusion: From our study we can conclude that, organophosphorus is a self-poisoning important clinical problem in developing world. Because of limited guide therapy, properly study is needed for seeking treatment which could help to reduce mortality and morbidity.

Keywords: organo phosphorus, insecticides, agricultural area.

Copyright @ 2020: This is an open-access article distributed under the terms of the Creative Commons Attribution license which permits unrestricted use, distribution, and reproduction in any medium for non-commercial use (NonCommercial, or CC-BY-NC) provided the original author and source are credited.

\section{INTRODUCTION}

Organophosphates (OP) are used as insecticides in agricultural and domestic settings throughout the world. The mechanism of action is through the inhibition of the enzyme acetylcholinesterase, leading to the accumulation of acetylcholine at cholinergic synapses.

On a worldwide basis, pesticides are responsible for hundreds and thousands of cases of acute poisoning and many thousands of deaths each year. Vast majority of these deaths are result of suicidal consumption of organo phosphorous compounds.

The excess acetylcholine causes constant acetylcholine receptor triggering, resulting in malfunction of the autonomic, somatic and central nervous systems. Clinical manifestations of OP poisoning lead to acute cholinergic crisis [1].

Although parasympathetic overstimulation tends to predominate, the overstimulation causes a clinically indistinguishable pattern of symptoms which, however, tend to be milder and of shorter duration [2]. Their common availability renders OP insecticide poisoning a worldwide health problem affecting millions of patients. With a high fatality rate $[3,4]$.

The majority of these poisonings appear to be an act of self-harm. Thousands die each year, especially in the Asian Pacific region, where pesticide poisoning is the most frequent cause of fatal self-poisoning [4]. In this study our main goal is evaluation of autopsy study of organo phosphorus poisoning in patients.

\section{OBJECTIVE \\ General objective}

- To evaluation of autopsy study of organo phosphorus poisoning in patients.

\section{Specific objective}

- To detect symptoms of the exposure to organophosphates of the patients

- To identify poisoning level of the patients 


\section{Methodology}

\begin{tabular}{|l|l|}
\hline Type of study & Retrospective study \\
\hline Place of study & Sylhet MAG Osmani Medical College \\
\hline Study period & January 2015 to January 2017. \\
\hline Study population & 75 patients included in the study who were fulfilled criteria. \\
\hline Sampling technique & Purposive \\
\hline
\end{tabular}

\section{Study procedure}

During the study. Face to face interview of the participants were conducted with the semi-structured, pre-tested questionnaire. The interview was conducted anonymously and privately as much as possible. Before preceding the data collection, the detail of the study was explicitly explained to each eligible respondent and informed written consents from the respondents were obtained.

\section{Data Analysis}

Data were entered in the template of Statistical program, SPSS-15 after necessary editing and coding. Descriptive statistics were generated for sociodemographic variables and were presented with relative frequency. For assessing the compilations and health seeking pattern relevant data were analyzed along with the descriptive statistics. Cross tabulation of the selected complication and key health seeking practice variables were done to explore the association through chi square test at a significance level of $\mathrm{P}<0.05$.

\section{RESUlT}

In table-1 shows age distribution of Opc poisoning cases where most of the patients belong to 21-30 years age group, $40 \%$. The following table is given below in detail:

Table-1: Age distribution of Opc Poisoning Cases

\begin{tabular}{|l|c|c|}
\hline Age group in years & No of victims & Percentage \\
\hline$<10$ years & 5 & $7 \%$ \\
\hline$(21-30)$ years & 30 & $40 \%$ \\
\hline$(31-40)$ years & 25 & $34 \%$ \\
\hline$(41-50)$ years & 10 & $13 \%$ \\
\hline$>50$ years & 5 & $7 \%$ \\
\hline Total $=$ & $\mathbf{7 5}$ cases & $100 \%$ \\
\hline
\end{tabular}

In figure-1 shows distribution of $\mathrm{OPC}$ poisoning cases according to the gender where $57 \%$ patients were male, which was $14 \%$ higher than female. The following figure is given below in detail:

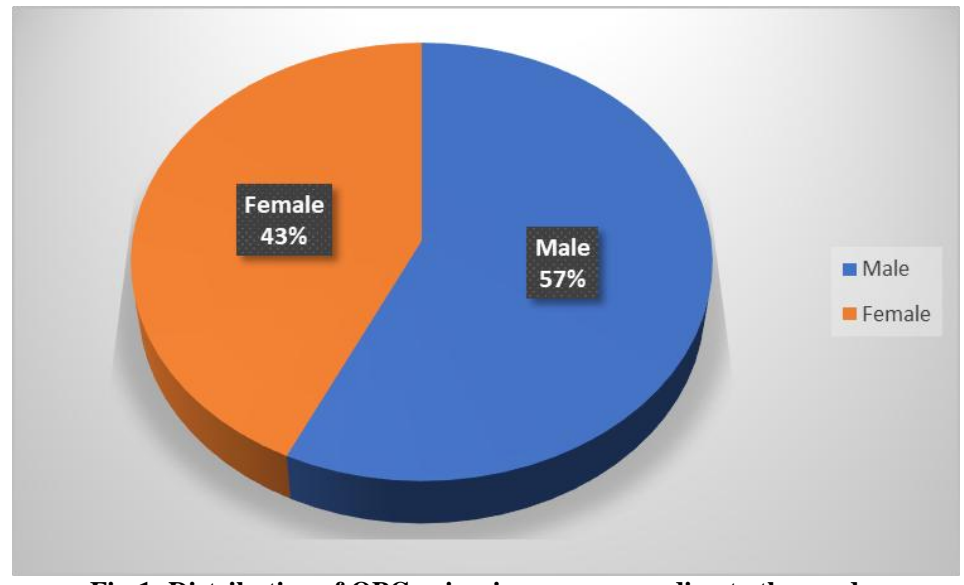

Fig-1: Distribution of OPC poisoning cases according to the gender

In table-2 shows distribution of OPC Poisoning cases by professions. 50\% worked as a agriculture area/ farmers. The following table is given below in detail:

Table-02: Distribution of OPC Poisoning cases by professions

\begin{tabular}{|l|c|c|}
\hline Profession & No of Victim & Percentage \\
\hline Agriculture working / Farmers & 40 & $50 \%$ \\
\hline House wife & 30 & $40 \%$ \\
\hline Others & 5 & $7 \%$ \\
\hline Total= & $\mathbf{7 5}$ & $100 \%$ \\
\hline
\end{tabular}

In figure-2 shows distribution of the patients according to purpose of organophosphates where $75 \%$ people used it for suicide and $25 \%$ people used it accidentally. The following figure is given below in detail: 


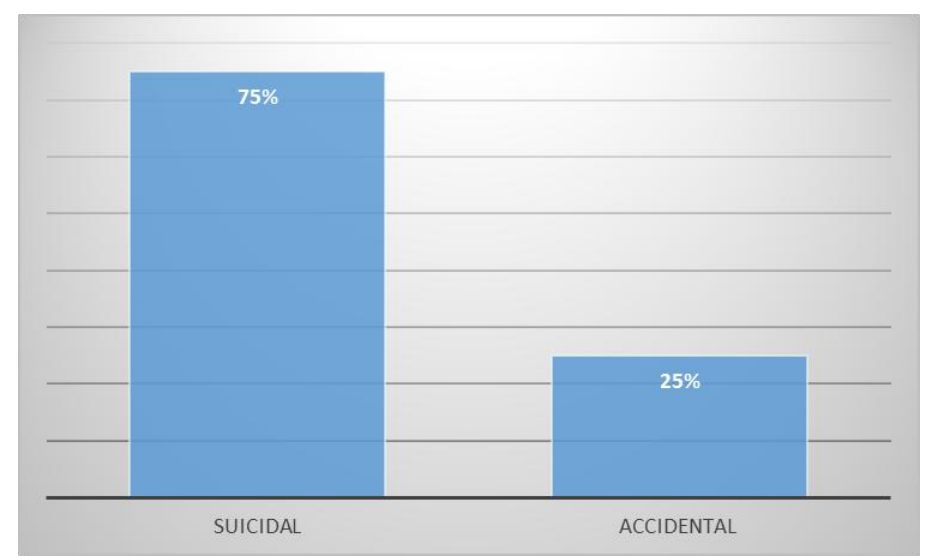

Figure-2: Distribution of the patients according to purpose of organophosphates

\section{DISCUSSION}

In China and South-East Asia pesticides account for about 300000 suicides each year [5]. Another study suggested that each year worldwide there is 3 million acute poisoning with 220000 deaths [6].

In Bangladesh poisoning is an important health problem causing around 2000 deaths per year.12 Selfpoisoning constitutes more than half of the total poisoning cases admitted in hospital.13 Most of the poisoning cases may have some reasons for taking poison. Which is quite similar to our study where $75 \%$ people used it for suicide and $25 \%$ people used it accidentally.

OPC poisoning in a country like Bangladesh is not only a public health problem but also related to economics and culture. There is great need to enhance stress on prevention of poisoning. A coordinated and comprehensive response is needed to make any impact.

In our study most of the cases belonged to the age group of 21-30 years which is similar to the one study [7]. In a country like India this is the age group where the youth have to shoulder the responsibilities of the family. However, some cannot cope with this burden and hence this age group contributes for maximum deaths due to poisoning. In our study, males and females comprised 57\% and $43 \%$ of the cases respectively; male patients were $14 \%$ higher than female. This male predominance was also seen the one report [8].

Another report from India in 1993-1994 analyzed 559 cases of poisoning 14 and aluminium phosphide was found to be the most common poison. The scenario was not different from these reports and agrochemicals continue to be the most common agents responsible for suicidal and/or accidental poisoning [9]. According to National Crime Records Bureau India, every 5 minutes one person commits suicide and 7 attempts to kill themselves, forming about 100000 deaths per year [10].
In a study of India, suicide rate was found highest in the state of Kerala [11]. Majority of the victims belonged to the group 14-34 years and OPC was the most common agent used for suicidal purpose [12]. In Sri Lanka, many of hospital admissions each year are for agrochemical poisoning with over a thousand deaths annually. Of these, about three-quarters are self-administered, and the rest are occupational and accidental [13]. In Sri Lanka another study showed that incidence of suicide due to poisoning was more than $80 \%$, followed by hanging which constituted $10.7 \%$ [14]. However, changing use from the most toxic pesticides to less toxic pesticides has had a remarkable effect in Sri Lanka and the suicide rate has fallen by $50 \%$ over ten years since such legislation was passed.[15-16] In USA, during 1980, out of total fatalities $49.7 \%$ were suicides and $39.5 \%$ were accidental by agrochemical poisoning[17].

\section{CONCLUSION}

From our study we can conclude that, organophosphorus is a self-poisoning important clinical problem in developing world. Because of limited guide therapy, properly study is needed for seeking treatment which could help to reduce mortality and morbidity.

\section{REFERENCE}

1. Corriols M, Marin J, Berroteran J, Lozano LM, LundbergI, Thorn A. The Nicaraguan Pesticide PoisoningRegister:constant underreporting.Int J Health Serv.2008.38(4):773-87

2. Kenneth D Katz. Organophosphatetoxicity:Medscape. May 2016.

3. WHO in collaboration with UNEP,1990. Public HealthImpact of Pesticides used in Agriculture. Updated June. 2007, WHO, Geneva.

4. Knight B, Pekka S. Agrochemical poisoning. In: Knight's forensic pathology. 3rd edn. London: Arnold. 2004: 352-380.

5. .DJ Somasundaram, S Rajadurai.Acta Psychiatr Scand.1995,91:1-4.

6. MR Phillips, Y Li X Zhang. 1995-99.Lancet. 2002,359: 835-840 
7. Joseph, S Abraham, JP Muliyil, K George, J Prasad, SMinz, BMJ. 2003,24,1121-1122.

8. Singh A, Harish D, KumarA.JPunjab Acad ForensicMed Toxicology. 2013;13(2)

9. Thomas SHL, White J. Poisoning. In: Colledge NR, Walker BR, Ralstone SH. Davidson's principles \& practice of medicine. 21st edn. Churchill Livingstone Elsevier. 2010: 203-228.

10. Minton NA, Murray VSG. A review of organophosphorus poisoning. Med Toxicol. 1988; 3: 350-357.

11. Tafury J, Roberts J. Organophosphorus poisoning. Ann Emerg Med. 1987; 16: 193-202.

12. Jeyaratnam J. Health problems of pesticide usage in the Third World. British journal of industrial medicine. 1985 Aug;42(8):505.
13. Bangladesh Health Bulletin UMIS, Director General of Health Services, Dhaka; 2001.

14. Galgali RB, Sanjeeb R, Ashok MV, Appaya P, Srinivasan K. Psychiatric diagnosis of selfpoisoning cases; a general hospital study. Indian Journal of Psychiatry. 1998; 40(3): 254-259.

15. Karalliede L, Senanayake N. Acute organophosphorus insecticides poisoning in Sri Lanka. Forensic Sci Int 1988; 36: 97-100.

16. Hettiarachchi J, Kodithuwakka GCS, Chandrasiri N. Suicide in Southern Sri Lanka. Medicine, Science and Law. 1988; 28(3): 248-251.

17. Klein-Scwartz W, Smith GS. Agricultural and horticultural chemical poisoning. Morbidity and mortality in United States. Ann Emerg Med. 1997; 29: 232-238. 